und P. Grabar, J. Immunol. 74, 158 (1955). - 11. Scheiffarti, F., H. Götz, H. Warnatz und K. Koch, im Druck. - 12. Scheiffarth, F., H. Warnatz und H. Götz, Med. Welt 49, 2216 (1961). - 13. Uriel, J., Bull. Soc. Chim. biol. 105, Suppl. I, 39 (1957). - 14. Uriel, J., H. Götz und P. Grabar, Schweiz. med. Wschr. 87, 431 (1957). - 15. MOORE, H. D., L. LEVIN und G. K. SMelser, J. biol. Chemistry 157, 723 (1945). - 16. W ATERSTRADT, K., Ärztl. Forsch. 1, 181 (1952). - 17. LOVE, R. M., J. Sci. Food Agric. 9, 257 (1958). - 18. Partmann, W., Probleme d. Ernährung durch Gefrierkost; Wissenschaftl. Veröffentl. d. Dtsch. Gesellschaft für Ernährung, 12, 12, Dr. D. Steinkopf Verlag, Darmstadt (1964). - 19. Moran, T., Proc. Roy. Soc. 98 B, 436 (1925). - 20. LeA, G. H., J. Sci. Food Agric. 8, 1 (1957). - 21. Len, G. H. und J. C. Hawke, Biochem. J. 52,
105 (1952). - 22. Kürinau, I., Probleme d. Ernährung durch Gefrierkost; Wissenschaftl. Veröffentl. d. Dtsch. Gesellschaft für Ernährung, 12, 9, Dr. D. Steinkopf Verlag Darmstadt (1964). 23. Monzini, A., La tachipessi applicata alla conservazione delle carni. Nota II. Influenca sulle attività proteolitiche della catepsine. Estratto dagli Annali della sperimentazione. Agraria (Nuova serie) 6 S. (Roma 1953). - 24. LyNEN, F. und H. W. KALB, Ann. Acad. Sci. Fennicae, Ser. A II 60, 471 (1955). - 25. Privitera, C. A., D. Greipf, D. R. Strength, M. Angtin und H. Pinkerton, J. biol. Chemistry 23, 524 (1958). - 26. Alford, J. A. und D. A. Pierce, J. Food Sci. 26, 518 (1961). - 27. Balls, A. K. und J. W. Tucker, Ind. Engng. Chem. 30, 415 (1938). - 28. Kiermeier, F., Biochem. Z. 318, 275 (1947). 29. Sizer, J. W. und E. S. Josephison, Food Res. 7, 201 (1942).

Professor Dr. med. F. Scheiffarth Med. Klinik der Universität 852 Erlangen

Krankenhausstr, 12

\title{
Dünnschichtchromatographische Trennung konjugierter Serumgallensäuren
}

\author{
Von B. Frosch und H. WAGENER \\ Aus der Medizinischen Klinik der Universität Heidelberg - Ludolf-Krebl-Klinik (Direktor : Prof. Dr. G. Schettler)
}

(Der Schriftleitung zugegangen am 26. August 1964)

\begin{abstract}
Es wird eine Methode zur dünnschichtchromatographischen Trennung der konjugierten Serumgallensäuren beschrieben. Nach Fällung der Serumeiweißbestandteile mit heißem absolutem Alkohol können Serumlipide entweder dünnschichtchromatographisch-präparativ oder durch Extraktion abgetrennt werden.

A method is described for the separation of conjugated serum bile acids by thin layer chromatography. After precipitation of serum proteins with hot, absolute alcohol, serum lipids can be separated either by preparative thin layer chromatography or by extraction.
\end{abstract}

Über den Gallensäuregehalt des Duodenalexkretes bzw. des Gallensaftes konnte durch Anwendung der papierchromatographischen Trenntechnik mit quantitativen Bestimmungsverfahren eine gewisse Klarheit geschaffen werden. Besonders das von SJövall ermittelte Verfahren gelangte zu breiterer Anwendung. Damit lassen sich die freien Gallensäuren, die Glycinkonjugate und die Taurocholsäure von den beiden taurinkonjugierten Dihydroxycholansäuren (Taurocheno- und. Taurodesoxycholsäure) trennen. Doch ist dieses Verfahren durch die Notwendigkeit, in mehreren Fließmitteln auf- und absteigend $\mathrm{zu}$ chromatographieren, umständlich. Einfacher gelingt eine Trennung der Gallensäuren mit Hilfe der Dïnnschicbtchromatographie. Hierzu wurden Fließmittelsysteme von GäNSHIRT und Mitarbeitern, Eneroth, Hofmann, Hamilton, Frosch und Wagener angegeben. Allerdings können dünnschichtchromatographisch bisher nur die freien Gallensäuren vollständig getrennt werden. Bei den konjugierten Gallensäuren sind die für die Dihydroxycholansäuren erzielten $R_{\mathbf{R}^{-}}$ Wertunterschiede zu gering.

Demgegenüber wurden chromatographische Untersuchungen der Serumgallensäuren bisher selten durchgeführt. Rudmann und Kendall geben ein säulenchromatographisches Verfahren an, CAREY trennt freie Serumgallensäuren papierchromatographisch nach SjövaLL. Ebenfalls papierchromatographisch können freie
Serumgallensäuren als Methylester nach OsBorn und Mitarbeitern getrennt werden. Schließlich haben SJövall und Mitarbeiter die gaschromatographische Trennung freier Gallensäuren nach Reinigung des Serums an Ionenaustauschersäulen durchgeführt. Über die Trennùng freier Serumgallensäuren durch Dünnschichtchromatographie mit nachfolgender quantitativer Bestimmung wurde von FrosCH berichtet.

Das im folgenden beschriebene Verfahren, die konjugierten Serumgallensäuren dünnschichtchromatographisch zu trennen, hat die Abtrennung der Serumeiweißkörper und einiger Lipide zur Voraussetzung. Die Trennung von Lipiden und Gallensäuren kann dabei dünnschichtchromatographisch-präparativ oder durch Extraktion erreicht werden.

\section{Methode}

\section{Reagenzien}

Kieselgel „G“ zur Dünnschichtchromatographie; Merck Nr. 7731

n-Butanol; Merck Nr. 988

Eisessig p. a.; Merck Nr. 60

Petroläther Sdp. 40-60 ; Merck Nr. 909

Diäthyläther; Merck Nr. 921

Äthanol abs.; Merck Nr. 972

Heptan; Merck Nr. 4365 


\section{Gallensäuren}

Cholsäure („,C"), Chenodesoxycholsäure („CDC“) und Desoxycholsäure („DC“) lieferte die „California Corporation for Biochemical Research", Los Angeles. Vor Gebrauch wurden diese Gallensäuren säulen-chromatographisch nach Norman bzw. GäNshirt und Mitarbeitern gereinigt. Danach erwiesen sie sich bei der dünnschichtchromatographischen Prüfung als nahezu rein. Die Taurin- bzw. Glycinkonjugate ${ }^{1}$ ) der Cholsäure, Chenodesoxycholsäure und Desoxycholsäure wurden nach Bergström und Norman hergestellt. Die dabei erhaltenen Reaktionsprodukte (TC, TCDC, TDC, GC, GCDC, GDC) wurden an Kieselgelsäulen (Merck Nr. 7733) mit n-Butanol/Eisessig/Wasser (10:1:1) gereinigt und nach Umkristallisation dünnschichtchromatographisch geprüft.

\section{Ausführung}

Die Herstellung der Dünnschichtplatten erfolgt nach Stafll. Dic lufttrockenen Platten werden offen aufbewahrt Die Auftragung der zu trennenden Substanzgemische erfolgt als 1,5-2 cm lange Banden $2 \mathrm{~cm}$ über dem unteren Plattenende mit genügendem Abstand vom Plattenrand. Laufstrecke: $16 \mathrm{~cm}$; Laufzeit: 3,5 bis 4 Stdn. Als Fließmittelsysteme wurden verwendet: Zur Trennung der Gallensäuren: Butanol/Eisessig/Wasser $(10: 1: 1)=$ „BEW“. Zur Abtrennung der Lipide: Petroläther/Äther/Eisessig (85: $15: 1)$ $=$ „PAE“.

Zur Extraktion der konjugierten Serumgallensäuren wird frischgewonnenes Blut zentrifugiert, das Serum dekantiert. $5 \mathrm{ml}$ Serum werden $35 \mathrm{~m} /$ absolutem Äthanol tropfenweise zugesetzt. Danach wird kurz auf $70^{\circ}$ erwärmt und nach Abkühlen $12 \operatorname{Stdn}$ bei $-10^{\circ}$ zur Erzielung einer vollständigen Eiweißfällung aufbewahrt. Vom ausgefallenen Eiweiß wird abzentrifugiert. Das zurückbleibende Eiweiß wird dreimal mit 70-proz. heißem Äthanol (je ca. $10 \mathrm{~m} l$ ) gewaschen. Das Filtrat und der beim Zentrifugieren erhaltene Überstand werden im Vakuum bei ca. $60^{\circ}$ zur Trockne gebracht. Eventuell auftretendes Schäumen kann durch Zusatz einiger Tropfen abs. Äthanols beseitigt werden. Der Rückstand wird $4 \mathrm{mal} \mathrm{mit} \mathrm{je} 4 \mathrm{~m} /$ abs. Äthanols unter Rühren mit dem Glasstab extrahiert. Dabei lösen sich die Gallensäuren, während Mineralsalze zurückbleiben. Die vereinigten Äthanolextrakte werden in einem 100-ml-Rundkolben vereinigt, der Alkohol wird im Vakuum abgezogen. Danach wird der Rückstand $4 \mathrm{mal} \mathrm{mit} \mathrm{je} 5 \mathrm{ml} 50$-proz. Äthanol aufgenommen. Die äthanolischen Lösungen werden in einem 50-ml-Schütteltrichter vereinigt. Nach Zugabe von je $10 \mathrm{ml}$ Äther und Heptan wird ausgeschüttelt. Die obere Phase wird verworfen. Die Unterphase wird noch $2 \mathrm{mal}$ mit je $20 \mathrm{ml}$ einer Oberphase ausgeschüttelt, die aus Äther/Heptan/Äthanol/ Wasser $(1: 1: 1: 1)$ getvonnen wird. Die bei diesem Ausschütteln entstehenden Oberphasen werden wiederum verworfen. Die alkoholisch-wässerige Unterphase wird im Vakuum zur Trockne gebracht und der Rückstand mit $1,0 \mathrm{ml}$ abs. Alkohol aufgenommen. Zur chromatographischen Trennung werden $0,05-0,1 \mathrm{ml}$ aufgetragen.

Statt mit der beschriebenen Extraktion kann eine Abtrennung von Lipiden auch durch präparative Dünnschichtchromatographie erzielt werden. Hierzu wird der nach Eiweißfällung dekantierte Uberstand auf Volumina von $0,5-1,0 \mathrm{ml}$ eingeengt, die als möglichst schmale, $12 \mathrm{~cm}$ lange Bande auf die Dünnschicht aufgetragen werden. Dic chromatogtaphische Trennung erfolgt im Fließmittel „PAE“. Dabei bleiben Gallensäuren, Phosphatide

1) Abkürzungen : „TC“ = Taurocholsäure; ,TDC“ $==$ Taurodesoxycholsäure; „TCDC“ = Taurochenodesoxycholsäure; „GC“ = Glycocholsäure; „GDC“ = Glycodesoxycholsäure; "GCDC" = Glycochenodesoxycholsäure; "TC" und "GC" werden als Trihydroxycholansäuren (,THC“), Chenodesoxycholsäure und Desoxycholsäure als Dihydroxycholansäuren („DHC“) bezeichnet. und Monoglyceride an der Auftragstelle zurück, während andere Lipide abgetrennt werden. Deshalb wird die Kieselgelschicht an der Auftragstelle abgetragen, in einen Erlenmeyer-Kolben gebracht, mit absolutem Alkohol überschichtct und ca. 12 Stdn. bei $50^{\circ}$ mit Hilfe eines Magnetrührers gerührt. Nach Uberspülen in Zentrifugengläser wird $30 \mathrm{Min}$. bei $4000 \mathrm{U} / \mathrm{Min}$. zentrifugiert, der Uberstand dekantiert und im Vakuum zur Trockne gebracht. Der Rückstand wird in $1 \mathrm{~m} /$ absolutem Äthanol aufgenommen. Zum Auftragen einer $1,5 \mathrm{~cm}$ breiten Bande werden $0,1 \mathrm{~m} /$ verwendet.

\section{Ergebnisse}

Die Abbildung 1 zeigt die dünnschichtchromatographische Trennung von Lipiden nach Chromatographie mit dem Fließmittel „PAE“. In der Laufrichtung betrachtet, finden sich fünf Hauptbanden, die freiem Cholesterin, freien Fettsäuren und Triglyceriden entsprechen; bei den beiden obersten Banden handelt es sich um Cholesterinester und Fettsäureäthylester. An der Auftragstelle bleiben Gallensäuren, Phosphatide und Monoglyceride. Zwischen Auftragstelle und freiem Cholesterin liegt eine zarte Bande, bei der es sich möglicherweise um Diglyceride handelt.

Um sicher zu sein, daß mit den getrennten Lipiden keine Gallensäuren wandern, wurden die Lipidbanden einzeln eluiert und in "BEW" rechromatographiert. Gallensäureverdächtige Banden waren hierbei nicht zu erkennen. Wird nunmehr der bei Chromatographie in „PAE“ an der Auftragstelle verbliebene Rückstand eluiert und in „BEW“ rechromatographiert (Abb. 2) so findet man jetzt Phosphatide und Monoglyceride an
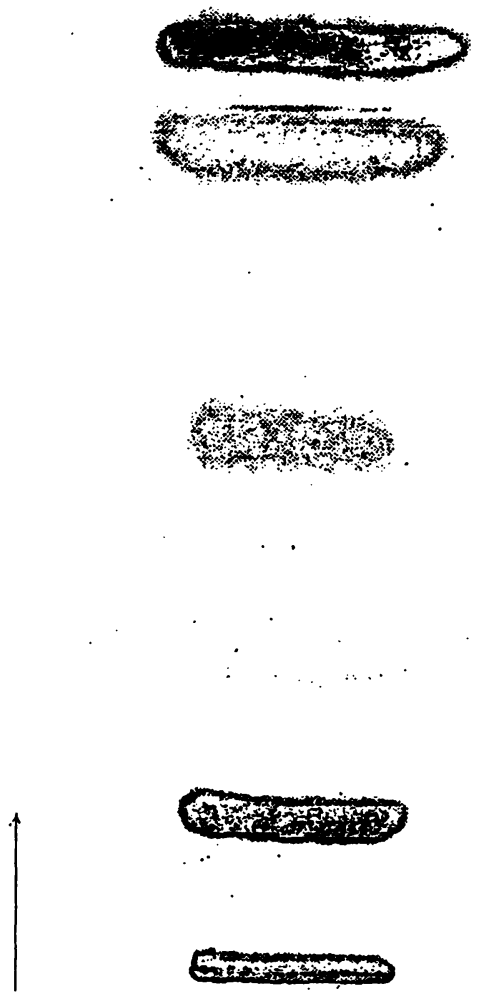

Abb. 1

Dünnschïchtchromatographische Trennung von Serumlipiden in Petroläther/Äther/Eisessig 


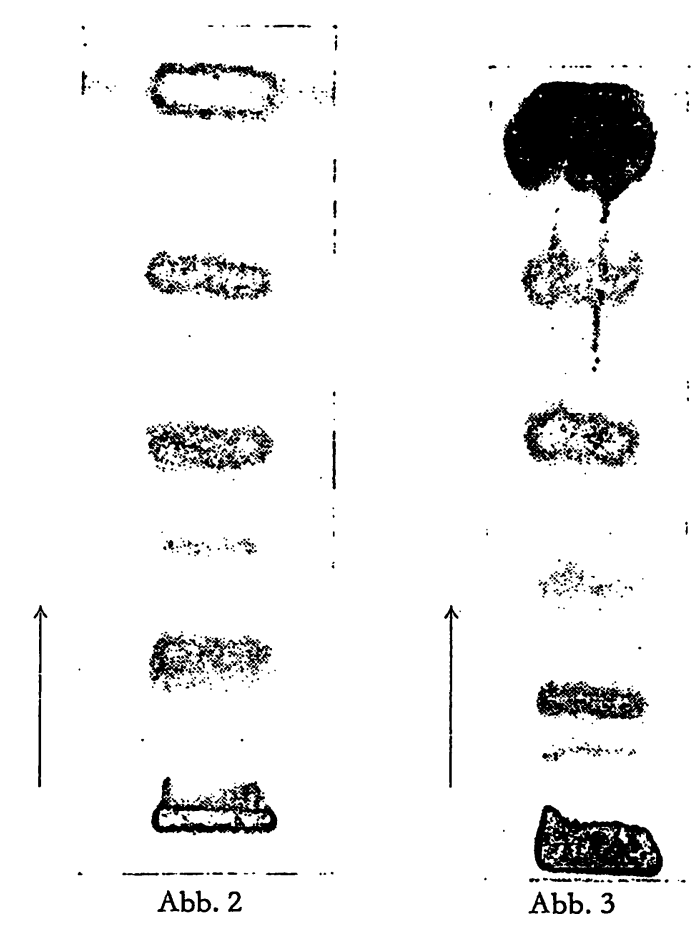

Abb. 2

Dünnschichtchromatographische Trennung in Butanol/Eisessig/ Wasser $(10: 1: 1)$ des bei Chromatographie in Petroläther/Äther/ Eisessig an der Auftragstelle verbliebenen Rückstandes.

Die Hauptbanden entsprechen mit Auftragstelle und Fließmittelfront Bilirubin, TC, TCDC und TDC, GC, GCDC und GDC, Phosphatiden und Monoglyceriden

\section{Abb. 3}

Dünnschichtchromatographische Trennung des äthanolgefällten Serums in Butanol/Eisessig/Wasser

der Front als Bestätigung, daß die chromatographische Abtrennung der Lipide in „PAE“ unvollständig war. Des weiteren werden mehrere Hauptbanden sichtbar, deren Färbe-Verhalten und $R_{\mathrm{P}}$-Werte mit denen gereinigter Gallensäuren übereinstimmen. In der Fließrichtung handelt es sich dabei um TC, TCDC und TDC, GC, GCDC und GDC. Dazwischen treten schwächere Banden auf, die nicht identifiziert werden konnten.

Bringt man nur äthanolgefälltes Serum zur dünnschichtchromatographischen Trennung in „BEW“"

(Abb. 3), so sieht man an der Auftragstelle einen erheblichen Rückstand und außerdem an der Fließmittelfront einen großen Lipidfleck, der über das obere Drittel der Laufstrecke schmiert.

Zusätzlich ist die übrige Laufstrecke, von einzelnen gallensäurehaltigen Banden unterbrochen, unsauber. Diese Abbildung demonstriert die Schwierigkeit, die einer chromatographischen Trennung der Gallensäuren des Serums entgegensteht und die in dem quantitativen Mißverhältnis zwischen den überwiegenden Lipiden und den in geringer Konzentration vorkommenden Gallensäuren zu sehen ist. Allerdings kommt es unter Zuhilfenahme der dünnschichțchromatographischen Trenntechnik nicht darauf an, alle Lipide abzutrennen. Es genügt, wenn dieses quantitative Mißverhältnis beseitigt wird, um zu einer befriedigenden dünnschichtchromatographischen Trennung der Gallensäuren zu gelangen (s. Abb. 2). Dabei bleibt bei der chromatographischen Entwicklung in „BEW“ Bilirubin großenteils an der Auftragstelle.

Weiter interessiert, ob die nach Äthanolfällung des Serums und dünnschichtchromatographischer Trennung in "BEW" erhaltenen Banden noch Lipide enthalten. Dazu wurden die nach Trennung in „BEW“ erhaltenen Banden einschließlich Auftragstelle - insgesamt 12 Banden - eluiert und in „PAE“ rechromatographiert. Erwartungsgemäß trennt sich dabei die Front in die in Abbildung 1 beschriebenen Banden. Die Gallensäuren bleiben an der Auftragstelle; außerdem werden einige unbekannte, nur in geringer Konzentration vorliegende Substanzen von der Auftragstelle abgetrennt.

Diese Versuche zeigen, daß eine dünnschichtchromatographische Trennung der Gallensäuren nach Äthanolfällung der Serumeiweißbestandteile in „BEW“ nicht möglich ist, da die quantitativ überwiegenden Lipide die Trennung erheblich stören. Trennt man einige Lipide präparativ-dünnschichtchromatographisch in "PAE“ ab, bleiben Gallensäuren, Phosphatide und Monoglyceride und weitere, unbekannte Substanzen in geringer Konzentration an der Auftragstelle zurück. Bei der Rechromatographie der eluierten Auftragstelle in „BEW“ wandern Phosphatide und Monoglyceride zur Front, die Gallensäuren werden befriedigend getrennt. Zwischen den Gallensäurebanden sind weitere, zarte Banden sichtbar, die nicht identifiziert werden konnten. Prüft man die „BEW“-getrennten Banden auf Lipidrückstände durch Rechromatographie in „PAE“, so erweisen sie sich bis auf geringe Verunreinigungen, deren Identität unklar ist, als lipidfrei.

Wenn auch präparativ-dünnschichtchromatographisch eine ausreichende Abtrennung der Lipide in „PAE“ und danach eine befriedigende Trennung der konjugierten Serumgallensäuren in „BEW“ erreicht werden kann, hat dieses Verfahren einen Nachteil. Das Eluieren dèr Gallensäuren nach Abtragen der Auftragstelle ist zeitraubend und nicht quantitativ. In vielen Versuchen waren im Kieselgelrückstand trotz vielstündigen Eluierens mit absolutem Alkohol nach Dekantieren des äthanolischen Überstandes noch Gallensäuren nachweisbar. Damit ist das geschilderte Vorgehen nur für qualitative Untersuchungen der konjugierten Serumgallensäuren geeignet. Diese Schwierigkeit wird durch das beschriebene Extraktionsverfahren umgangen. Abbildung 4 zeigt die dünnschichtchromatographische Trennung konjugierter Serumgallensäuren in „BEW“ nach vorausgegangener Lipidextraktion, Die Hauptbanden stellen in der Fließrichtung TC, TCDC und TDC, GC, GCDC und GDC dar. Die $R_{\mathrm{f}}$-Werte der nativen Serumgallensäuren entsprechen denen gereinigter käuflicher Gallensäuren. Wiederum treten zwischen den Gallensäuren schmale Banden unbekannter Identität in geringerer Konzentration auf. Außerdem ist zu erkennen, da $B$ die Lipidextraktion unvollständig ist. An der Front ist eine Lipidbande sichtbar. Doch ist die vorausgegangene Lipidabtrennung ausreichend. Die dünnschichtchromatographische Trennung der konjugierten Serumgallen- 


\section{tisy}

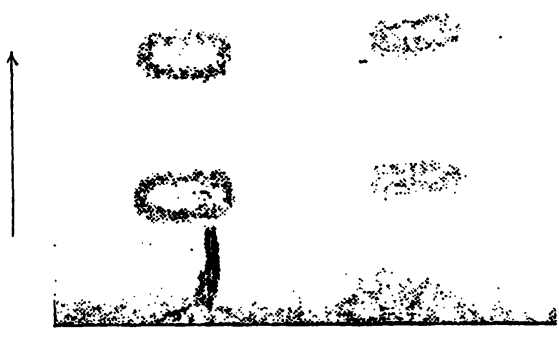

Abb. 4

Dünnschichtchromatographische Trennung konjugierter Serumgallensäuren in Butanol/Eisessig/Wasser.

a) Serumextrakt

b) Leitchromatogramm: TC, TCDC und TDC, GC, GCDC und GDC

säuren wird durch den verbleibenden Rest nicht gestört. Zusätzlich wurde geprüft, ob bei den einzelnen Schritten des Extraktionsverfahrens Verluste an Gallensäuren auftreten. Hierzu wurden die Rückstände hydrolysiert, nach Ansäuern mit Äther ausgeschüttelt und als äthanolische Lösungen in Toluol/Eisessig/Wasser (5:5:1) dünnschichtchromatographisch geprüft. Dabei waren keine gallensäureverdächtigen Bande nachweisbar.

\section{Diskussion}

Das jetzt beschriebene Verfahren zur dünnschichtchromatographischen Trennung konjugierter Serumgallensäuren basiert auf einer schonenden Eiweißfällung, um die konjugiert vorliegenden Gallensäuren - nicht zu hydrolysieren. Das von JOSEPHSON vorgeschlagene Verfahren, die Serumeiweißbestandteile mit einer äthanolischen Bariumhydroxyd/Bariumazetatlösung zu fällen, ist dazu ungeeignet. Bereits bei dem vorgeschriebenen einmaligen kurzen Aufkochen, sogar bei nur kurzem Erwärmen auf $70^{\circ}$, wird ein Teil der Konjugate ausweislich einer dünnschichtchromatographischen Prüfung des Rückstandes hydrolysiert. Bei der Fällung der Serumeiweißbestandteile mit heißem Äthanol werden keine Gallensäuren freigesetzt. Im Eiweißrückstand sind keine Gallensäuren nachweisbar. Nach Fällung der Eiweißbestandteile mit Äthanol behält das Serum allerdings seine gelbliche Tönung, was aber keinen Nachteil darstellt, da bei der späteren chromatographischen Trennung das Bilirubin an der Auftragstelle zurückbleibt.

Die Hauptschwierigkeit, die einer dünnschichtchromatographischen Trennung der konjugierten Serumgallensäuren entgegensteht, ist das quantitative Úberwiegen der Lipide. Diese Schwierigkeit kann dadurch beseitigt werden, daß einige Lipide durch präparative Dünnschichtchromatographie abgetrennt werden. Ein von MANGOLD und TuNA angegebenes Fließmittelsystem wurde hierzu abgewandelt, um den $R \mathrm{f}$-Wertunterschied zwischen Auftragstelle und erster Lipidbande zu vergrößern. Die konjugierten Gallensäuren bleiben dabei an der Auftragstelle und werden nach Elution bei der Rechromatographie in „BEW“ getrennt. Da die Elution von Gallensäuren aus Kieselgel zeitraubend und nicht quantitativ ist, bleibt die Anwendung dieses einfachen Verfahrens auf qualitative Untersuchungen beschränkt.

Das Fließmittelsystem „BEW“ wurde von GäNSHIRT, Koss und Mortanz angegeben. Es hat wie die von Frosch und Wagener, bzw. ENeroth und HoffmanN beschriebenen Fließmittel den Nachteil, daß die DHCKonjugate nicht getrennt werden, so daß also die Banden in der Fließrichtung TC, TCDC und TDC, GC, GCDC und GDC darstellen. - Die Extraktion einiger Serumlipide - ohne Verluste an Gallensäuren - in einer von BORGSTRÖM vorgeschlagenen Abwandlung des Verfahrens von Blankenhorn und Ahrens hat gegenüber der präparativen dünnschichtchromatographischen Lipidabtrennung den Nachteil, aufwendiger zu sein. Sowohl bei der präparativ-dünnschichtchromatographischen Trennung wie bei der Extraktion ist die Abtrennung der Lipide unvollständig. Eine vollständige Abtrennung der Lipide wird gleichzeitig mit der dünnschichtchromatographischen Trennung der Gallensäuren erzielt.

\section{Literatur}

1. Bergström, S. und A. Norman, Acta Chem. Scand. 7, 1126 (1953). - 2. Blankenhorn, D. H. und E. H. Ahrens JR., J. biol. Chemistry 212, 69 (1955). - 3. BORGSTRÖM, B., G. LUNDH und A. Hofmann, Gastroenterology 45, 229 (1963). - 4. CAREY, J. B. JR., Science 123, 892 (1956). - 5. ENERoth, P., J. Lipid Res. 14, 11 (1963). - 6. FrosCh, B. und H. WAGENER, diese Z. 1, 187 (1963). - 7. Frosch, B. Klin. Wschr., 43, 262 (1965). - 8. Gänshirt, H., F. W. Koss und K. Morianz, ArzneimittelForsch. 10, 943 (1960). - 9. Hamilton, J. G., Gaschrom.
Newsletter 4, (1963). - 10. HofmanN, A. F., J. Lipid Res. 3, 127 (1962). - 11. Josephoson, B., Biochem. J. 29, 1519 (1935). - 12. Mangold, H. K. und N. Tuna, Fed. Proc. 20, 268 (1961). - 13. Norman, A., Acta Chem. Scand. 7, 1413 (1953). - 14. Osborn, E. C., I. D. P. Wootton, L. C. DA. Siluva und S. SherLoCK, Lancet 2, 1049 (1959). - 15. RudMaN, D. und F. E. KenDALL, J. Clin. Invest. 36, 530 (1957). - 16. Syövall, J., Arkiv för Kemi 30, 317 (1955). - 17. Sjövall, J., D. Sandberg, K. Sıövall und D. A. Turner, Fed. Proc. 22, 198 (1963).

Dr. med. B. Frosch

Med. Univ.-Klinik (Ludolf-Krehl-Klinik)

69 Heidelberg, Bergheimcr Str. 58 